\title{
The Development of Central Pontine Myelinolysis in a Type 1 Diabetic Patient With Anti-Insulin Antibody and Similar Clinical Manifestations to Autoimmune Polyglandular Syndrome
}

\author{
Reo Yoshikawa ${ }^{a}$, Akahito Sako ${ }^{a}$, Hiroki Kitagawa ${ }^{a}$, Hidetaka Hamasaki ${ }^{\text {a }}$, Tomoka Okubo ${ }^{\text {a }}$, \\ Chika Hiraishi $^{a}$, Keigo Suzukia, Shuichi Mishima ${ }^{a}$, Hidekatsu Yanai ${ }^{\mathrm{a}, \mathrm{b}, \mathrm{c}}$
}

\begin{abstract}
Central pontine myelinolysis is a demyelinating disorder, which is commonly associated with the rapid correction of hyponatremia. We repot an 84-year-old type 1 diabetic woman with high level of anti-insulin antibody, who developed central pontine myelinolysis, in spite of a careful correction of hyponatremia. We believe that high level of anti-insulin antibody and similar clinical manifestations to autoimmune polygrandular syndrome such as Candidiasis, hypothyroidism, type 1 diabetes and liver cirrhosis possibly due to autoimmune hepatitis may be associated with the development of central pontine myelinolysis.
\end{abstract}

Keywords: Anti-insulin antibody; Autoimmune polyglandular syndrome; Central pontine myelinolysis; Insulin glulisine; Type 1 diabetes

\section{Introduction}

Central pontine myelinolysis (CPM) is a demyelinating disorder, which is commonly associated with the rapid correction of hyponatremia [1]. We describe a patient who developed CPM, in spite of a careful correction of hyponatremia, possibly due to high level of anti-insulin antibody and similar clinical manifestations to autoimmune polygrandular syndrome (APS).

Manuscript accepted for publication June 20, 2012

${ }^{a}$ Department of Internal Medicine, National Center for Global Health and Medicine Kohnodai Hospital, Chiba, Japan

${ }^{\mathrm{b}}$ Clinical Research Center, National Center for Global Health and Medicine Kohnodai Hospital, Chiba, Japan

${ }^{\mathrm{c}}$ Corresponding author: Hidekatsu Yanai, Department of Internal Medicine, Clinical Research Center, National Center for Global Health and Medicine Kohnodai Hospital, 1-7-1 Kohnodai, Ichikawa, Chiba 272-8516, Japan. Email: dyanai@hospk.ncgm.go.jp

doi: http://dx.doi.org/10.4021/jem112w

\section{Case Report}

An 84-year-old woman had subcutaneous nodules and uveitis due to sarcoidosis which was pathological diagnosed, and was treated by steroid and was diagnosed as having diabetes in 1978. She had been treated by oral anti-diabetic drugs until she had been treated by regular human insulin in 2003. In 2006, her anti-glutamic acid decarboxylase antibody (anti$\mathrm{GAD} \mathrm{ab})(65.2 \mathrm{U} / \mathrm{mL}$; normal range, $<1.5 \mathrm{U} / \mathrm{mL})$ and antiinsulin antibody $\left({ }^{125} \mathrm{I}\right.$-insulin binding rate, $65.2 \%$; normal, $<$ $0.4 \%$ ) were significantly elevated, and her plasma glucose control had been remarkably brittle. Switching from regular human insulin (10 units before every meal) to insulin lispro (6 units before every meal) in 2007 did not improve her glycemic control, and the treatment using insulin lispro (10 units before every meal) was switched to insulin glulisine in 2009. She developed ascites in October, 2010, and she lost appetite due to increased ascites and admitted to our hospital in February, 2011. Her body height, body weight and body mass index were $153 \mathrm{~cm}, 39 \mathrm{~kg}$ and $16.7 \mathrm{~kg} / \mathrm{m}^{2}$. An ab-

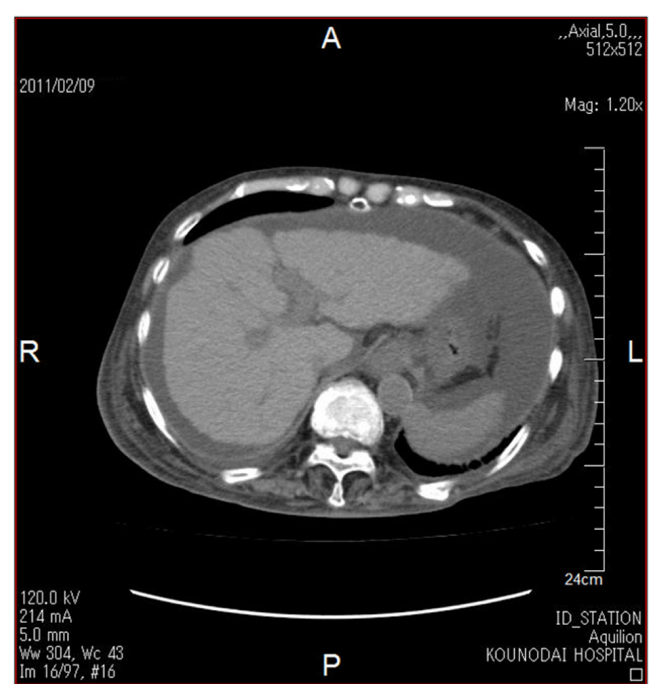

Figure 1. Abdominal computed tomography showing ascites and findings which suggest the existence of liver cirrhosis such as rough hepatic surface and atrophy. 

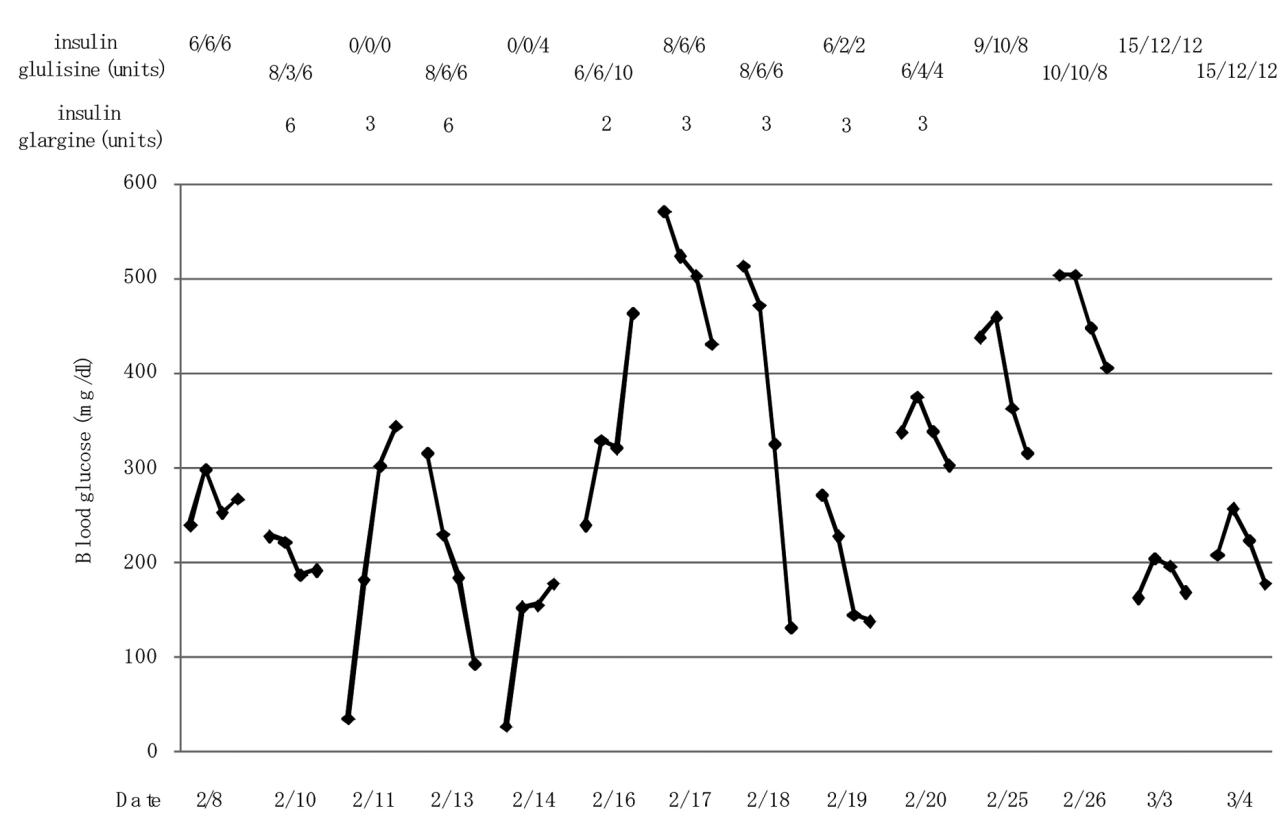

Figure 2. Changes in blood glucose Ievels at betore breaktast, lunch and dınner, and beatıme by switchıng trom the basal-bolus insulin therapy using insulin glargine to three pre-meal injections of insulin glulisine.

dominal computed tomography showed ascites and findings which suggest the existence of liver cirrhosis such as rough hepatic surface and atrophy (Fig. 1). Anti-HBV antibody and anti-HCV antibody were negative and HCV-RNA was not detected. Serum levels of hyaluronic acid $(305 \mathrm{ng} / \mathrm{mL}$; nor$\mathrm{mal}, \leq 50 \mathrm{ng} / \mathrm{mL})$, type III pro-collagen peptide $(0.84 \mathrm{U} / \mathrm{mL}$; normal, $0.3-0.8 \mathrm{ng} / \mathrm{mL}$ ) and type IV collagen $7 \mathrm{~S}$ domain ( $7.8 \mathrm{ng} / \mathrm{mL}$; normal, $\leq 6 \mathrm{ng} / \mathrm{mL}$ ) were elevated, supporting the existence of liver cirrhosis. Although a definitive pathological diagnosis by liver biopsy was not obtained, elevation of serum levels of $\operatorname{IgG}(2,391 \mathrm{mg} / \mathrm{dL}$; normal, 870 - 1,700 $\mathrm{ng} / \mathrm{mL}$ ), anti-liver kidney microsome-1 (LKM) antibody (17; normal, < 17), anti-single stranded-DNA IgG (90 AU/ $\mathrm{mL}$; normal, $\leq 25 \mathrm{AU} / \mathrm{mL})$ and anti-nuclear antibody $(160 \mathrm{x}$; normal, $<4 \mathrm{x}$ ) suggested the existence of autoimmune hepatitis. Further, hypothyroidism was found, although serum free thyroxine level (T4) $(0.83 \mathrm{ng} / \mathrm{dL}$; normal, $0.9-1.7 \mathrm{ng} /$ $\mathrm{dL})$ was normal, serum thyroid stimulating hormone (TSH) (14.45 $\mu \mathrm{IU} / \mathrm{mL}$; normal, $0.5-5.0 \mathrm{mIU} / \mathrm{mL}$ ) increased and free triiodothyronine (T3) $(2.16 \mathrm{pg} / \mathrm{mL}$; normal, $2.3-4.3 \mathrm{pg} /$ $\mathrm{mL}$ ) decreased. However, anti-thyroid peroxidase antibody (anti-TPO ab) and anti-thyroglobulin antibody (anti-TG ab) were not detected. Daily $50 \mu \mathrm{g}$ of levothyroxine sodium improved her thyroid function. Her glycemic control was very brittle due to significantly high level of anti-insulin antibody $\left({ }^{125} \mathrm{I}\right.$-insulin binding rate, $>90 \%$; normal, $<0.4 \%$ ). Her glycoalbumin (38.6\%; normal range, $11.0-16.0 \%)$ and anti-GAD ab $(35.0 \mathrm{U} / \mathrm{mL}$; normal range, $<1.5 \mathrm{U} / \mathrm{mL})$ levels were high. We started to use insulin glargine at bedtime. At the next morning after the use of insulin glargine (6 units), she showed severe hypoglycemia, and 2 - 3 units of insulin glargine did not improve her glucose control (Fig. 2). Therefore, we stopped the use of insulin glargine and increased dose of insulin glulisine, which significantly ameliorated her glucose control and also did not induce severe hypoglycemia (Fig. 2). She was discharged from our hospital in March, 2011.

In June, 2011, she was again admitted to our hospital due to consciousness disturbance. On the admission, her blood glucose (465 mg/dL) and plasma osmolality (308 mOsm/k; normal range, 276 - $292 \mathrm{mOsm} / \mathrm{k}$ ) were remarkably elevated and urinary ketone bodies were not detected, suggesting the development of hyperosmolar hyperglycemic syndrome (HHS). Serum glycoalbumin (38.3\%; normal range, $11.0-16.0 \%)$ and anti-insulin antibody $\left({ }^{125} \mathrm{I}\right.$-insulin binding rate, $89.3 \%$; normal, $<0.4 \%$ ) levels were slightly reduced as compared with those in February, 2011. Laboratory data showed increased leukocyte counts $(12,700 / \mu \mathrm{L})$ and anemia (hemoglobin $6.7 \mathrm{~g} / \mathrm{dL}$; normal range, 11.5 - $15.0 \mathrm{~g} / \mathrm{dL}$ ). Serum levels of blood urea nitrogen (BUN) $(168 \mathrm{mg} / \mathrm{dL}$; normal range, 8 - $22 \mathrm{mg} / \mathrm{dL})$, creatinine $(1.55 \mathrm{mg} / \mathrm{dL}$; normal range, $0.4-0.7 \mathrm{mg} / \mathrm{dL})$ and C-reactive protein levels (2.94 $\mathrm{mg} / \mathrm{dL}$; normal range, $0-0.3 \mathrm{mg} / \mathrm{dL}$ ) remarkably increased and serum albumin significantly decreased $(2.6 \mathrm{~g} / \mathrm{dL}$; normal range, 3.9 - $5.0 \mathrm{~g} / \mathrm{dL})$. Serum sodium $(113 \mathrm{mmol} / \mathrm{L}$; normal range, 138 - $146 \mathrm{mmol} / \mathrm{L}$ ) and chloride (84 mmol/L; normal range, 99 - $109 \mathrm{mmol} / \mathrm{L})$ levels decreased and potassium (6.3 $\mathrm{mmol} / \mathrm{L}$; normal range, 3.6 - $4.9 \mathrm{mmol} / \mathrm{L}$ ) level increased. Further, because she did not intake levothyroxine sodium, serum free T3 (1.49 pg/mL; normal, $2.3-4.3 \mathrm{pg} / \mathrm{mL})$ and 

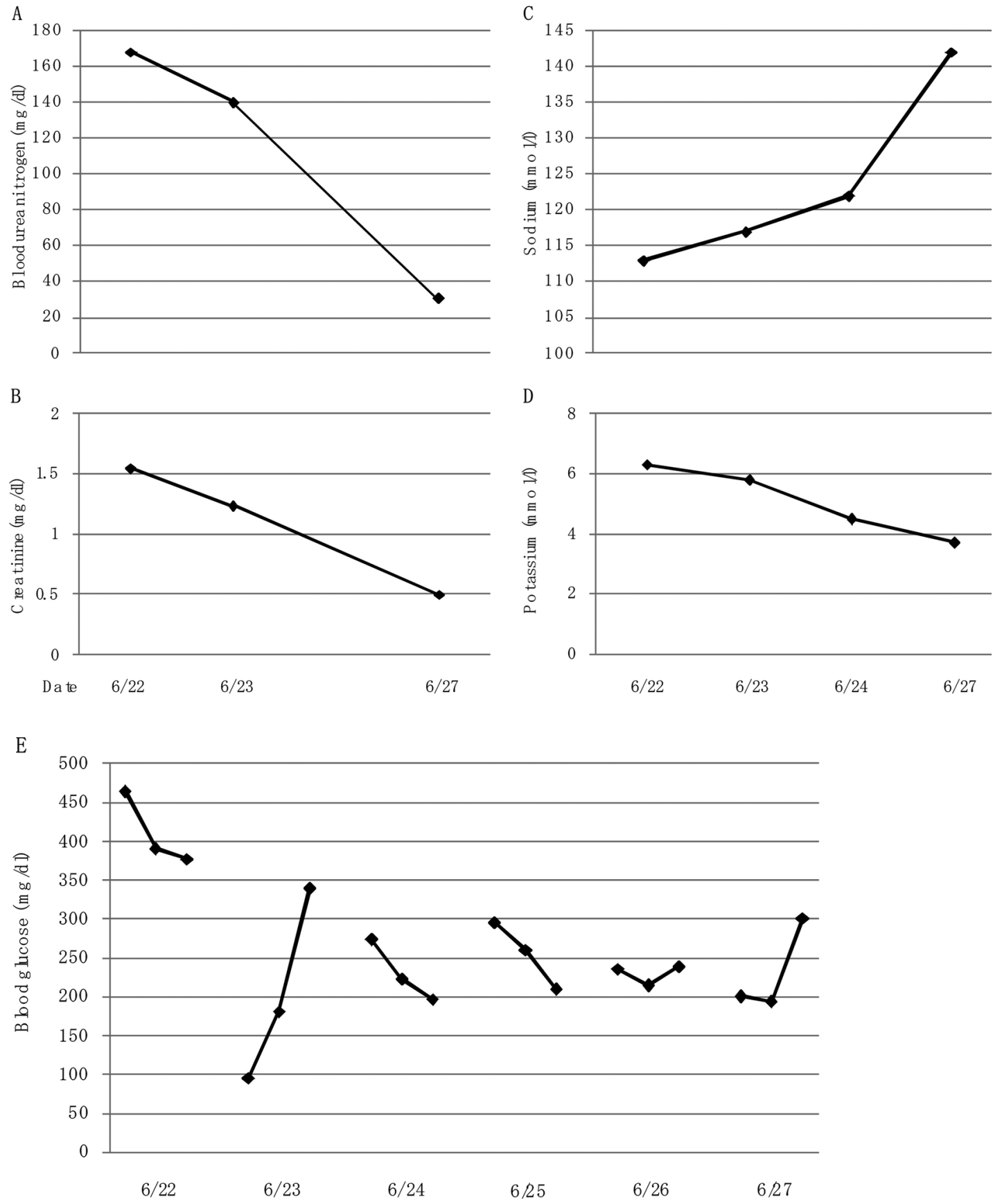

Figure 3. Changes in serum levels of blood urea nitrogen (A), creatinine (B), sodium (C) and potassium (D), and blood glucose (E) before the development of central pontine myelinolysis after the admission.

free T4 $(0.38 \mathrm{ng} / \mathrm{dL}$; normal, $0.9-1.7 \mathrm{ng} / \mathrm{dL})$ decreased, and serum TSH $(5.05 \mu \mathrm{IU} / \mathrm{mL}$; normal, $0.5-5.0 \mathrm{mIU} / \mathrm{mL})$ increased, showing hypothyroidism. To find the cause of dehydration, inflammation and anemia, we performed gastroenterological endoscopy, and we found esophageal ulcer and esophagitis with Candida. Appetite loss, minor bleeding and inflammation due to esophageal ulcer with Candida may be associated with her development of HHS. She was treated by transfusion and fluconazole, antifungal drug, and we did not infuse solution including high concentration of sodium such as $3 \% \mathrm{NaCl}$ solution to prevent the development of CPM. At the same time, we infused regular human insulin intravenously. Dehydration, acute renal failure, hyperglycemia and hyperkalemia were promptly ameliorated due to transfusion and insulin administration, however, in spite of a careful correction of hyponatremia, serum sodi- 

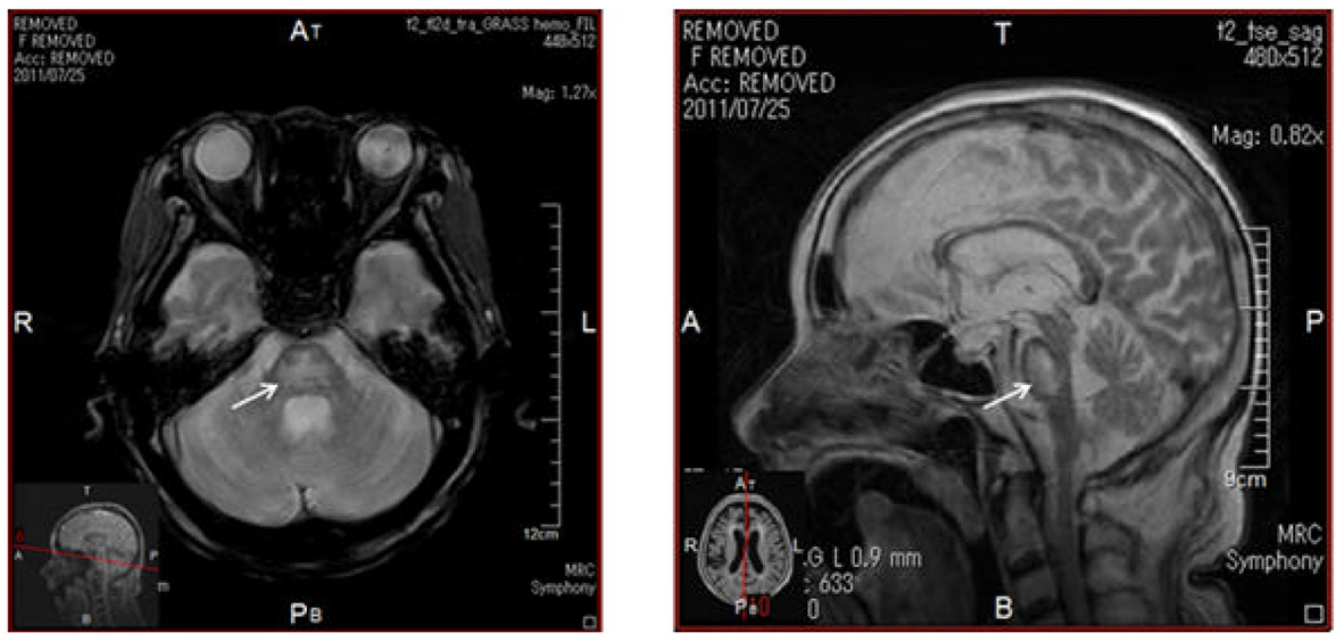

Figure 4. T2-weighted images of magnetic resonance imaging. Arrows indicate lesion of central pontine myelinolysis.

um rapidly increased (Fig. 3). These critical cares promptly improved her consciousness, however, her consciousness was again deteriorated in July 1, 2011. The magnetic resonance imaging showed the development of CPM (Fig. 4). Her consciousness was not recovered and she died at the end of August, 2011.

\section{Discussion}

This anti-GAD ab-positive patient was diagnosed as having diabetes, and had been treated by oral anti-diabetic drugs for 25 years, suggesting that her diabetes may be slowly progressive type 1 diabetes. Further, she showed a significantly high level of anti-insulin antibody. We previously reported that switching from the basal-bolus insulin therapy using insulin glargine to three pre-meal injections of insulin glulisine is effective in the treatment of a type 2 diabetic patient with long-acting insulin analogs-mediated immunogenic insulin resistance [2]. In this type 1 diabetic patient, switching to three pre-meal injections of insulin glulisine prevented severe hypoglycemia and significantly reduced the amplitude of glycemic excursions, and also decreased fasting blood glucose level.

She was also complicated with sarcoidosis, Candidiasis and possibly with autoimmune hepatitis. This patient showed similar clinical manifestations to autoimmune polygrandular syndrome (APS) (Table 1). Type 1 diabetes is observed in APS type 1, 2 and 3, and sarcoidosis, Candidiasis and autoimmune hepatitis are observed in APS type 3, type 1 and type 4, respectively [3]. Normal serum cortisol level at the morning $(18.1 \mu \mathrm{g} / \mathrm{dL}$; normal range, $4.0-19.3 \mu \mathrm{g} / \mathrm{dL})$ denied the existence of Addison's disease. Thyroid autoimmune disease is the major component disease of APS type 3 [3], in spite of showing hypothyroidism, she did not have an-
ti-TPO ab and anti-TG ab. Her anti-GAD ab level decreased from 65.2 (in 2006) to $35.0 \mathrm{U} / \mathrm{mL}$ in 2011. Anti-TPO ab and anti-TG ab might have decreased and disappeared.

Hypothyroidism is the major cause of hyponatremia [4], and thyroid hormone may be associated with the homeostasis of sodium. Serum albumin was remarkably decreased in this patient by liver cirrhosis possibly due to autoimmune hepatitis and also by loss of food intake due to esophageal ulcer with Candia. Serum albumin is very important to keep serum colloid osmolality. Liver dysfunction has been reported to be a risk factor for CPM [5]. Serum levels of BUN, sodium and glucose have been used for calculation of serum osmolality, indicating an importance of these parameters for serum osmolality [6]. Diabetes also has been suggested to be a risk factor for CPM [7]. The development of CPM in patients with diabetic ketoacidosis (one case) and HHS (one case) was reported $[8,9]$. In this patient, a significantly large amplitude of glycemic excursions due to anti-insulin antibody might induce a large amplitude of serum osmolality including sodium and BUN.

In conclusion, switching from the basal-bolus insulin therapy using insulin glargine to three pre-meal injections of insulin glulisine was also effective in the treatment of a type 1 diabetic patient with long-acting insulin analogs-mediated immunogenic insulin resistance and hypoglycemia. We experienced a patient who developed CPM in spite of a careful correction of hyponatremia, possibly due to high level of anti-insulin antibody and similar clinical manifestations to APS.

\section{Acknowledgement}

This work was supported by the Grant of National Center for Global Health and Medicine (22-120). 

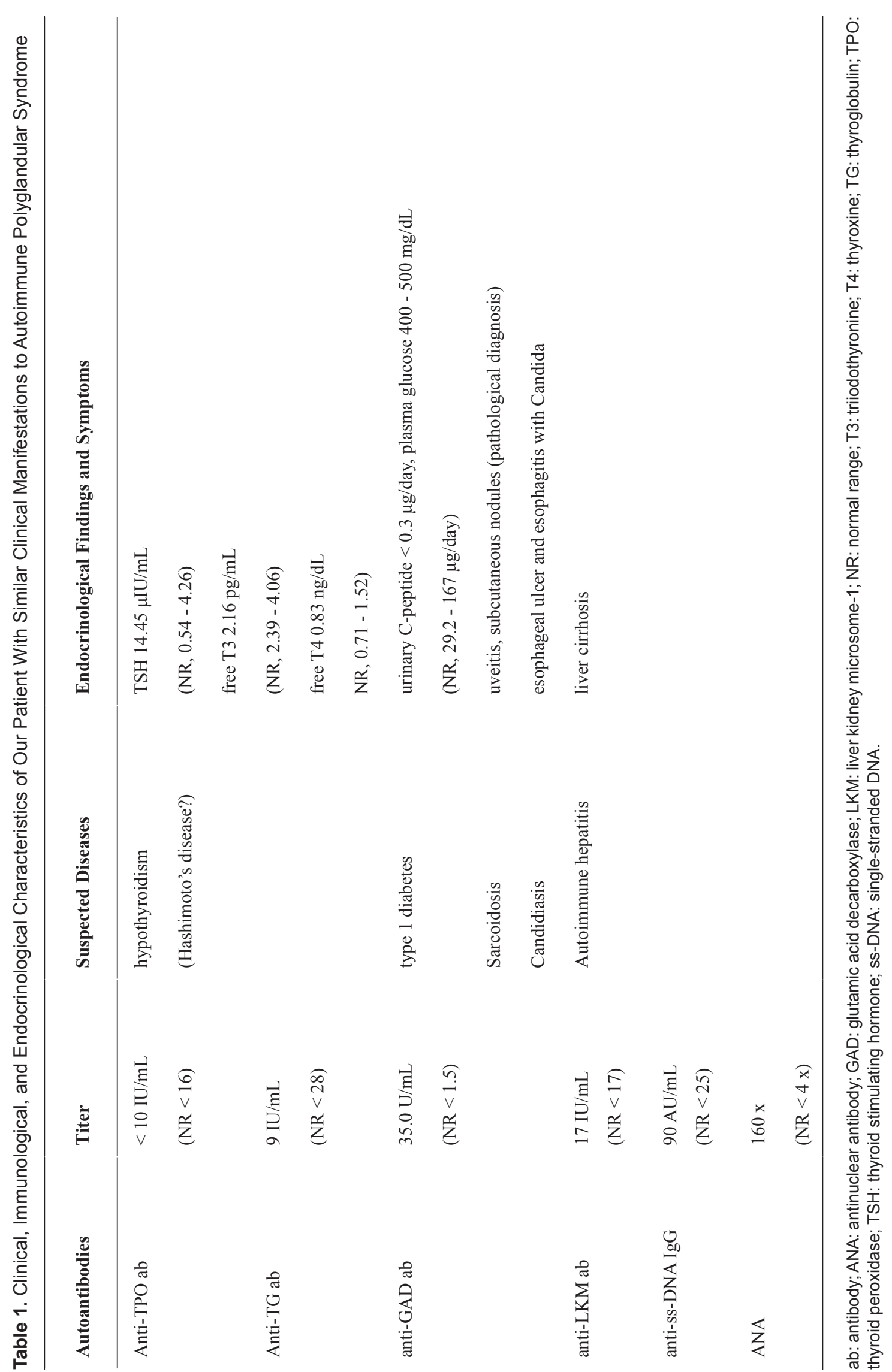


\section{References}

1. Lampl C, Yazdi K. Central pontine myelinolysis. Eur Neurol. 2002;47(1):3-10.

2. Yanai H, Yoshimi T, Hamasaki H. Switching to three pre-meal injections of insulin glulisine from the basalbolus insulin therapy improves glycemic control in a patient with type 2 diabetes who had anti-insulin antibody. Int J Diabetes Dev Ctries. 31(4):240.

3. Betterle C, Dal Pra C, Mantero F, Zanchetta R. Autoimmune adrenal insufficiency and autoimmune polyendocrine syndromes: autoantibodies, autoantigens, and their applicability in diagnosis and disease prediction. Endocr Rev. 2002;23(3):327-364.

4. Liamis G, Milionis HJ, Elisaf M. Endocrine disorders: causes of hyponatremia not to neglect. Ann Med. 2011;43(3):179-187.

5. Lee EM, Kang JK, Yun SC, Kim KH, Kim SJ, Hwang KS, Lee SG. Risk factors for central pontine and extra- pontine myelinolysis following orthotopic liver transplantation. Eur Neurol. 2009;62(6):362-368.

6. Rasouli M, Kalantari KR. Comparison of methods for calculating serum osmolality: multivariate linear regression analysis. Clin Chem Lab Med. 2005;43(6):635640 .

7. Ichikawa H, Murakami H, Katoh H, Hieda S, Kawamura M. Central pontine lesions observed with MRI in four diabetic patients. Intern Med. 2008;47(15):1425-1430.

8. Roldan-Valadez E, Osorio-Peralta S, Hernandez-Matinez P, Sandoval-Gonzalez C, Casian-Castellanos G. Early MRI findings of central pontine myelinolysis following "rapid" correction of hyponatraemia during diabetic ketoacidosis. A curious pontine lesion (2003:12b). Eur Radiol. 2004;14(3):549-551.

9. Mao S, Liu Z, Ding M. Central pontine myelinolysis in a patient with epilepsia partialis continua and hyperglycaemic hyperosmolar state. Ann Clin Biochem. 2011;48(Pt 1):79-82. 